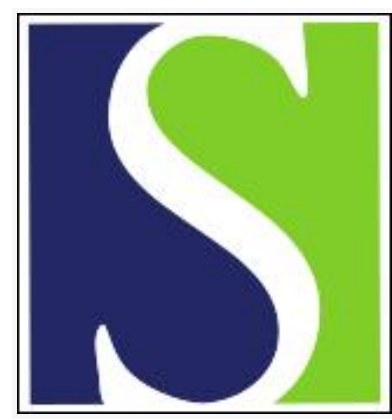

Scand J Work Environ Health 2009;35(5):349-360

https://doi.org/10.5271/sjweh.1348

Issue date: 00 Oct 2009

Prospective assessment of neuropsychological functioning and mood in US Army National Guard personnel deployed as peacekeepers

by Proctor SP, Heaton KJ, Dos Santos KD, Rosenman ES, Heeren T

Affiliation: Military Performance Division, US Army Research Institute of Environmental Medicine, Kansas St, Building 42, Natick, MA 01760, United States. susan.proctor@us.army.mil

Refers to the following text of the Journal: 1996;22(2):124-132

Key terms: assessment; deployment; military; mood; neurobehavior; neuropsychological functioning; peacekeeper; peacekeeping; US Army National Guard

This article in PubMed: www.ncbi.nlm.nih.gov/pubmed/19730757 


\title{
Prospective assessment of neuropsychological functioning and mood in US Army National Guard personnel deployed as peacekeepers ${ }^{1}$
}

\author{
by Susan P Proctor, DSc, ${ }^{2,3,4}$ Kristin J Heaton, PhD, ${ }^{2}$ Kathryn Dutille Dos Santos, MPH, ${ }^{5}$ Erik S Rosenman, \\ $\mathrm{MPH},{ }^{6}$ Timothy Heeren, $\mathrm{PhD}^{7}$
}

\begin{abstract}
Proctor SP, Heaton KJ, Dos Santos KD, Rosenman ES, Heeren T. Prospective assessment of neuropsychological functioning and mood in US Army National Guard personnel deployed as peacekeepers. Scand J Work Environ Health. 2009;35(5):349-360.
\end{abstract}

\begin{abstract}
Objective The present study examined the impact of deployment on neuropsychological functioning and mood in Army National Guard personnel. We hypothesized that deployment on a peacekeeping mission, compared to non-deployment, would result in reduced proficiencies in neuropsychological performance and negative mood changes, and that such changes would relate to working in a high-strain job (high demands/low control), in accordance with Karasek's demand-control model.
\end{abstract}

Methods This prospective cohort study involved 119 male soldiers (67 participants examined before and after deployment to the Bosnia operational theatre and 52 non-deployed soldiers assessed twice over a comparable period).

Results Unit-level adjusted, multivariate analyses found that deployed soldiers, compared to their non-deployed counterparts, demonstrated reduced proficiency in tasks involving motor speed [unstandardized coefficient $\mathrm{B}=-3.88,95 \%$ confidence interval $(95 \% \mathrm{CI})-6.38--1.39$; $\mathrm{B}=-3.84,95 \% \mathrm{CI}-5.55--2.14$; dominant and nondominant hand, respectively and sustained attention $(\mathrm{B}=0.031,95 \% \mathrm{CI} 0.009-0.054)$, along with decreased vigor $(\mathrm{B}=-2.71,95 \% \mathrm{CI}-3.63--1.77)$. Deployed soldiers also showed improved proficiency in a working-memory task $(\mathrm{B}=-0.098,95 \% \mathrm{CI}-0.136--0.060)$ with less depression symptomatology $(\mathrm{B}=-3.19,95 \% \mathrm{CI}-5.26--1.13)$. Work stress levels increased over time in both deployed and non-deployed groups, but observed deployment effects remained significant after accounting for a high-strain job.

Conclusion The observed change in performance associated with peacekeeping deployment compared to non-deployment (slowed processing speed, reduced motor speed and reported vigor, together with improved proficiency in a working memory task) suggests an adaptive response to mission occupational stressors. This pattern does not appear to be influenced by working in a high-strain job. Further study is required to examine whether these results reflect transient or permanent changes in functioning.

Key terms deployment; military; neurobehavior; peacekeeping.

In a recent prospective study of US Army soldiers deployed as part of Operation Iraqi Freedom, war-zone deployment was associated with reduced performance proficiencies within neuropsychological domains of sustained attention, learning, memory, and mood, along with improvements in reaction time - a performance pattern suggestive of a biologic response to traumatic stress (1). However, deployment as a peacekeeper encompasses a generally different set of stressors including workload changes, isolation, ambiguity, and boredom, reflective of occupational functions inherent in the mission (2-6). Prospective assessment of neuropsychological impairment and mood patterns can provide an efficient, objective, and non-invasive method

1 Initial study design and summary aspects of the study have been previously presented as posters at the American Psychological Association/National Institute for Occupational Safety and Health (APA/NIOSH), Work, Stress and Health Conferences held in 2003 and 2008.

2 Military Performance Division, US Army Research Institute of Environmental Medicine, Natick, Massachusetts, United States.

3 Research Service, VA (Veterans Affairs) Boston Healthcare System, Boston, Massachusetts, United States.

4 Department of Environmental Health, Boston University School of Public Health, Boston, Massachusetts, United States.

5 Southeast Center for Healthy Communities, Brockton, Massachusetts, United States.

6 Eidetics (Division of Quintiles Consulting), Boston, Massachusetts, United States.

7 Department of Biostatistics, Boston University School of Public Health, Boston, Massachusetts, United States.

Correspondence to: Dr SP Proctor, Military Performance Division, US Army Research Institute of Environmental Medicine, Kansas St, Building 42, Natick, MA 01760, United States. [E-mail: susan.proctor@us.army.mil] 
to gauge the effect of deployment on the functioning of the central nervous system (CNS), and thus potential longer-term impacts on occupational and psychosocial functioning.

Since the 1991 Gulf War, several investigations have examined relationships between specific stressors associated with deployment (eg, traumatic stress, environmental neurotoxicants) and patterns of CNS functioning using neuropsychological measures $(7,8)$. However, deployment-specific conclusions have been influenced by methodological challenges such as no pre-deployment examination, minimal to no inclusion of objective measures of performance, lack of comparable non-deployed groups, and post-deployment assessments often conducted several years following deployment (9). Several recent studies have focused on occupational and operational stressors related to peacekeeping and humanitarian missions among military personnel and the role these stressors play in job attitudes, general psychological or affective strain, and military job performance $(2,10,11)$. But, to date, limited attention has been paid to the impact of stress due to changes in occupational, or potentially conflicting, roles over a deployment on cognitive and related CNS functional abilities. This is a particular concern in the case of National Guard and Reserve forces due to their dual civilian and military occupational loads. In the years following the 1991 Gulf War, several studies found that National Guard and Reserve members were more likely to report postwar health problems compared to active duty personnel $(12,13)$. Several reasons were hypothesized: potential contrasts in pre-deployment health risk factors and deployment training preparation, differences in stressors and experiences while deployed, and differences in post-deployment support structures. Furthermore, particularly in deployment scenarios involving minimal traumatic stressors, it has been suggested that changes in workload dimensions during-deployment, relative to pre-deployment levels, may play a role in post-deployment health effects.

Both Seleye's and Hockey's theories of stress and human performance describe how the degree and types of workplace stress can lead to (mal)adaptive performance changes (14-16). In addition, introduced in 1979, Karasek's demand-control model $(17,18)$ illustrates the manner in which occupational stress, characterized by the level of psychological job demands and the degree of job control present in the work environment, produces strain. Job demands include not having enough time to complete tasks and excessive workloads. Job control refers to having the capability or opportunity to make job decisions and the amount of skill needed to perform the job. Karasek's model specifies four job types: high-strain (high demands/low control), low-strain (low demands/high control), active (high demands/high control), and passive (low demands/low control). The strain hypothesis of the model predicts that working in a high-strain job presents the highest risk for adverse physical and psychological health outcomes and well-being. Work stress characterized by higher demands (ie, overtime) and diminished control (ie, assembly-line work) in a civilian industrial environment has been associated with less proficient neuropsychological performance within the domains of attention and executive function, and current mood (19). It has been recognized that aspects of job strain impact general psychological health among military cohorts (20-25). But, to our knowledge, there is limited understanding of the influence that occupational stressors present during deployment operations, and more specifically during peacekeeping missions (eg, boredom, work overload, or job ambiguity), may have on neuropsychological functioning and mood. Knowledge about whether and how job stress might impact neuropsychological performances in a military work environment provides an important step towards better understanding broader post-deployment health and readiness, and identifies an additional focal point for training and protective strategies.

The aim of this prospective cohort study was to assess the impact of deployment on neuropsychological functioning and mood in Army National Guard (ARNG) personnel. Based on the conceptualization that neuropsychological changes reflect CNS performance responses when confronted with occupational stress, we hypothesized that deployed personnel (hereafter "deployers") would perform more poorly than their non-deployed counterparts (hereafter "non-deployers") - particularly within domains involving attention and cognitive processing - and would report more negative mood symptomatology. Additionally, we hypothesized that deployment, compared to non-deployment, would result in increased stress (higher demands together with reduced job control), and that working in a high-strain job (high demands, low control) would account for the a priori hypothesized deployment effects. Therefore, the analyses addressed two core questions: (i) Are there changes in neuropsychological functioning and mood associated with serving on a peacekeeping deployment? If yes, (ii) are the observed deployment-related effects associated with work stress (eg, working a high-strain job) among the deployed group (compared to the non-deployed), and thus supportive of the strain hypothesis in Karasek's demand-control model? Reports from earlier missions to the Bosnia operational theatre under Operation Joint Guard indicated the limited presence of life-threatening stressors $(26,27)$, thus minimizing the confounding influences of severe traumatic stress on neuropsychological functioning and mood. 


\section{Methods and procedures}

We obtained approvals from the human subject review committees of the Boston University Medical Center and the US Army, Office of the Surgeon General. Also, the state-level ARNG Adjutant General reviewed and supported logistical aspects related to the research project. All participants provided written informed consent prior to their participation.

\section{Study design}

This report focuses on the impact of a peacekeeping deployment mission on neuropsychological functioning and mood. Therefore, within this prospective cohort study design, the analyses focused on data collected at Time 1 and Time 2 assessments (figure 1). The deployed group was seen prior to deployment (Time 1) and upon redeployment to the US from Bosnia (Time 2). The nondeployed group was assessed also at two points in time designed to coincide with the deployed group's Time 1 and Time 2 assessment interval.

\section{Study population and sampling procedures}

The ARNG units deployed to Bosnia in this study were members of a six-month Operation Joint Guard rotation [Stabilization Force 10 (SFOR10)] and were all male, infantry-type units. Therefore, the target population pool for this study included male soldiers serving in 2001 in units with anticipated deployment to Bosnia or within units of comparable service missions. At Time 1, 171 soldiers (93 deployers and 78 non-deployers) volunteered to participate in the study, however, due to time constraints, several participants were not able to complete the total protocol. A total of 158 participants ( 88 deployers and 70 non-deployers) completed all aspects of the core study protocol at Time 1. A final sample of 119 persons (67 deployers, 52 non-deployers) completed the core study protocol at both Time 1 and Time 2, representing a $75.3 \%$ follow-up participation rate. The principal reason for non-participation at Time 2 was geographic unavailability [ie, 21 of the 39 persons $(54 \%)$ had moved out of state and/or left military service]. Four persons (two deployers, two non-deployers) declined to participate at Time 2. No major differences in Time 1 baseline characteristics (eg, age, education, marital status) or outcome measures were observed between the participating and non-participating groups. (Results are available on request from the first author.)

The Time 1 assessment of the deployers was carried out in July and August 2001 during scheduled training weekends at respective unit armories, $1-2$ months prior to actual deployment and within 1-4 weeks of the soldiers' mobilization for further training out of state. Participants making up the non-deployed comparison group were recruited at their respective armories also during scheduled training periods between October and early December 2001. The Time 2 assessment of the deployed group was conducted within approximately three weeks of return to the US from Bosnia (March-April 2002), with $94 \%$ of the assessments completed within seven days of return. For non-deployers, the Time 2 assessment was conducted during scheduled training weekends at unit armories at a time comparable to the deployed group interval (May-July 2002).

For the non-deployers, the pace or tempo of operations post-September 2001 involved frequent activation ("on alert" status) and mobilization orders (assignment to temporary duty location) that were not anticipated during the planning of the study design. As such, a subset of the non-deployers $(\mathrm{N}=19)$ served within the US on activated status at some point between the Time 1 and Time 2 assessment. We anticipated that non-deployers serving on activated status might differ from other non-deployers and have accounted for this in our analysis scheme.

Sample size requirements for this study were estimated a priori. We computed a target sample size of 75 soldiers per group to provide $80 \%$ power in order to detect medium effect sizes (28) in neuropsychological and mood outcomes at baseline ( $\mathrm{d}=0.40$ in this case); this effect size level corresponds to an $8-15 \%$ difference in means between the two groups, depending on the outcome. Assuming 75\% follow-up and controlling

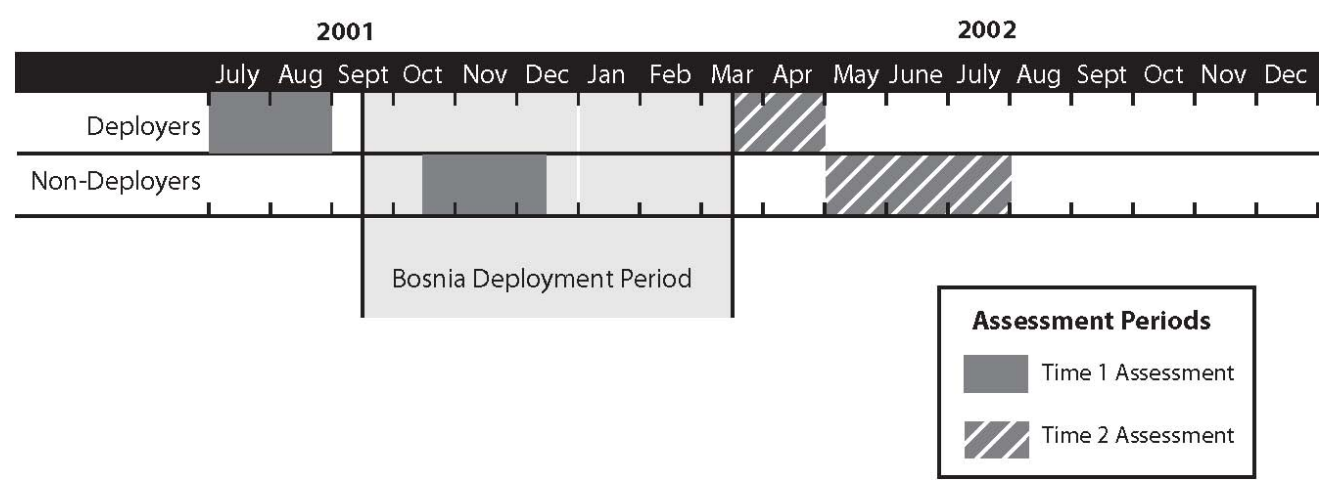

Figure 1. Study timeline. 
for baseline levels with an assumed correlation of 0.60 on average between Time 1 and Time 2 values, it was determined that we would have $80 \%$ power for detecting differences in Time 2 outcomes between the deployed and non-deployed study groups corresponding to effect sizes of approximately 0.40 . We assumed that the actual analyses would control for additional variables, resulting in increased power to detect differences or the ability to detect smaller effect sizes.

\section{Study protocol and measures}

The core study protocol was designed to take approximately 50-60 minutes and consisted of a battery of tasks from the Neurobehavioral Evaluation System [version 3, NES3, (Neurobehavorial Systems Inc, Atlanta, GA, USA)], a questionnaire, and a deployment history interview.

To address the study hypotheses, we examined performances within the functional domains of motor speed, simple and sustained attention, executive function, and working memory, along with reported current mood status. The neuropsychological task battery was presented to the participant on a personal computer with a touch screen monitor and took about 25 minutes to complete. All testing was conducted one-on-one (participant-to-examiner) in a semi-private space. The NES3 battery consists of tasks that have been validated in epidemiological and clinical settings $(29,30)$; the specific tasks administered in the current study were NES3 Finger Tapping (dominant and non-dominant hand), Sequences A and B (response time and number of errors), Digit Symbol (response time), and Continuous Performance Test involving letters (response time and number of errors). A further description of the NES3 can be found in an earlier publication (29).

To assess current mood status, all participants completed the Profile of Mood States [POMS (Educational and Industrial Testing Service, San Diego, CA, USA)], a 65-item adjective scale. Participants were presented with a series of mood adjectives and asked to rate the degree to which each adjective described their mood state over the preceding seven days, including the day of assessment. Ratings were made on a five-point scale $(0=$ not at all, $1=$ a little, $2=$ moderately, $3=$ quite a bit, $4=$ extremely). We computed subscale scores by summing the designated subscale items [n]; higher scores indicated more negative mood feelings for anger [12], tension [9], depression [15], confusion [7], and fatigue [7] and more positive feelings of vigor or activity [8]. In addition, we computed a total mood summary measure by subtracting the positive factor (vigor) from the sum of the negative subscale scores and adding a constant of 100 to eliminate negative values (31).

We assessed ARNG work stress levels at both Time 1 and Time 2 using the 14-item Job Content Questionnaire
(18, 32-34) and computed scoring using the algorithms presented by Landsbergis et al (33) that permit comparison to earlier US Quality of Employment Surveys. The scale provides a measure of the degree of decision latitude or job control (eg, opportunities to participate in decisionmaking processes and learning and job autonomy) (9items, score range 12-48; coefficient alpha at Time $1=0.79$ and Time 2=0.84), and psychological job demands, which included quantity of work and degree of time and work constraints (5-items, score range 12-48; coefficient alpha at Time $1=0.38$ and Time $2=0.54$ ). Also, we recomputed the job demands subscale using those three items we expected would better characterize job demands among military personnel ("requires working hard", "requires working fast", "have enough time to get job done"); this yielded coefficient alphas of 0.55 and 0.56 , at Time 1 and Time 2, respectively. We calculated a continuous measure of work stress by dividing job demands by job control [quotient term formulation (33)].

For hypothesis testing, we determined a simplified two-category measure of job strain, based on the quadrant term and median split formulation described by Bosma (35) and Landsbergis et al (33). Persons who simultaneously scored above the median for job demands and below the median for job control were defined as working in a high-strain job. We used the Time 1 median levels for the overall group to perform this categorization scheme at both Time 1 and Time 2. Persons in the other three quadrants of exposure were combined and defined as working in a non-high strain job.

Information on current age, education level, military service characteristics (such as rank), history of prior head injury, recent number of hours of sleep (mean number per day in the past week), caffeine use (mean number of drinks per day), recent level of alcohol use (mean number of drinks in the past week), and other lifestyle factors were obtained via questionnaire.

At Time 1, all participants were administered version 3 of the Wide Range Achievement Test for Reading [WRAT3 (Wide Range Inc, Wilmington, DE, USA)] and trial 1 of the Test of Memory Malingering [TOMM (Multi-Health Systems, Toronto, Ontario, Canada)]. We administered the WRAT3 reading test as a proxy measure for general academic knowledge to ensure the general comparability in academic abilities between groups. The TOMM is a simple 50 -item visual memory test assessing cognitive engagement. It was administered for the purpose of excluding persons from the analyses who exhibit low levels of engagement in the objective cognitive tests. Previous research examining the sensitivity and specificity of the TOMM has indicated that a score below 38 on trial 1 of the TOMM suggests insufficient task engagement (36).

To address the general comparability in functional health between groups, we administered the Medical 
Outcomes Study Short Form 12 adapted for Veterans [Veterans Rand 12-item Health Survey, VR-12 (37)]. The VR-12 provides summary scores for physical (physical component summary) and emotional (mental component summary) functional status, weighted and standardized to national norms with a mean of 50 and standard deviation equal to 10 . Higher scores indicate better functioning.

At both Time 1 and Time 2, post-traumatic stress disorder (PTSD) symptom severity (including symptoms pertaining to arousal, avoidance, and re-experiencing behaviors) was measured with the 17-item PTSD Checklist and scored according to diagnostic criteria algorithms $(38,39)$. The coefficient alphas of this sample for the PTSD Checklist were 0.92 at Time 1 and 0.93 at Time 2. To determine the prevalence for screening positive for presumptive PTSD, we applied the stricter screening criteria outlined by Hoge et al (40). Also, we assessed fatigue using the Checklist Individual Strength (CIS Fatigue, 41, 42), a scale used to examine prolonged fatigue among veterans of peacekeeping operations (43). The CIS Fatigue is a 20 -item scale that provides a summary score encompassing aspects of both mental and physical fatigue symptoms (eg, degree of feelings of physical exhaustion, whether thinking requires effort, and if one tires easily). Responses are scored on a 7point rating scale (ranging from $1=$ "yes, this is true" to $7=$ "no, this is not true") and computed such that higher scores indicate more fatigue. The coefficient alphas for the CIS Fatigue scores in this sample were 0.94 at Time 1 and 0.95 at Time 2. Unit cohesion (44) was examined via an abbreviated 12-item scale in which respondents were asked to rate how strongly they agree or disagree (on a 5-point scale) to statements about cooperation and support of unit members and leadership. The coefficient alpha for this sample was 0.93 at Time 1 and 0.92 at Time 2. At Time 2, all participants were asked to rate the degree of their ARNG job engagement (45), such as level of job commitment and responsibility for job performance, on a 4-item scale as an indicator of meaningful work. The coefficient alpha for the job engagement scale was 0.91 .

To ascertain the level and types of prevalent perceived stressors present during peacekeeping deployment in order to enable generalization to other peacekeeping missions, we asked deployers to rate the degree of impact (from "none" to "extreme") of Bosnia deployment experiences and/or events at Time 2, via the 23item Peacekeeping Incidences and Experiences Scale (46) and the 25-item Peacekeeping Deployment Stressors Scale $(47,48)$.

\section{Statistical analyses}

All statistical analyses were conducted with SPSS version 14.0 (SPSS Inc, Chicago, IL, USA) or SAS version
8 (SAS Institute, Inc. Cary, NC, USA). When data distributions departed significantly from the norm, raw scores were normalized via logarithmic transformation. No cases were excluded from the analyses, as no one scored below 38 on the TOMM. In less than $3 \%$ of cases, there were missing values for individual questionnaire scale items; these were replaced by the mean value of the individual's completed items for that measure if the participant responded to at least $50 \%$ of the items. If fewer than $50 \%$ of the items on a measure were completed, we did not compute summary scores. We reviewed and truncated outlier outcome values at 3 standard deviation from the mean when appropriate $(2.5 \%$ of cases at Time $1 ; 4 \%$ at Time 2).

The study incorporated a cluster-sampling design, with participants sampled within military unit groups. Therefore, to examine the primary and secondary hypotheses and account for the multi-level structure of the sampling, we performed generalized estimating equation (GEE) models with Time 2 neuropsychological task performances and mood as outcomes.

Deployment status (yes/no) served as the primary independent variable of interest and was categorized as those deployed to Bosnia (deployers) between Time 1 and Time 2 and those not deployed overseas during this timeframe (non-deployers). An independent variable was included in each regression model to account for 19 soldiers on activated status within the non-deployers (yes/no). Therefore, the deployed and activated, nondeployed groups were compared to the non-activated, non-deployed group via the analyses structure.

Age (in years) and educational level (any post high school education versus none) at Time 1 were included as covariates as they influence neuropsychological performance outcomes. Similarly, unit cohesion at Time 2 was also included in the GEE models run for each of the examined mood state outcomes. To account for baseline levels, we entered the Time 1 value for the Time 2 outcome measure of interest as a covariate in each model, creating a residualized index of longitudinal change (49). By including the Time 1 value in the core model set, we were able to examine the effect of deployment on the residual change for each outcome of interest.

Significance levels were adjusted via Bonferroni corrections to limit Type I error. We considered eight neuropsychological task outcomes involving objectively measured cognitive and motor abilities and six subjective mood state outcomes, resulting in adjusted significance levels of $\mathrm{P}=0.006(0.05 / 8)$ for objective performances and $\mathrm{P}=0.008(0.05 / 6)$ for subjective mood outcomes.

Our secondary hypothesis - higher levels of work stress influence the association between deployment status and task performance and mood outcomes - was examined in several analytic steps. First, to examine whether the observed significant relationships resulting 
through the primary hypothesis testing were explained by high work stress, we entered "being in a high-strain job at Time 2 (yes/no)" into the models (computed utilizing the 5 -item job demands scale). Second, to examine whether working a high-strain job might modify the deployment effects found in the primary hypothesis testing, we entered into the models the following computed interaction terms: [deployment (yes/no)] $\times$ [Time 2 high-strain job (yes/no)]; [activated, non-deployed (yes/no)] $\times$ [Time 2 high-strain job (yes/no)].

Using the adjusted difference in scores (unstandardized regression coefficient $\mathrm{B}$ ) divided by the unadjusted standard deviation, we determined the magnitude of the effect sizes for the significant results associated with deployment.

We performed sensitivity-type analyses to examine whether additional factors that have been shown to influence aspects of neuropsychological functioning and mood (eg, rank, hours of sleep, PTSD symptom severity, history of head injury, caffeine use, fatigue level, or job engagement) significantly influenced the deployment effect relationships observed when individually entered into the core GEE statistical models. As alcohol use was not permitted during deployment, we did not examine that potential factor in the sensitivity analyses. Since levels of support have been observed to influence the relationship between work strain and psychological symptomatology $(21,22)$, further post hoc analyses examined whether the interaction between deployment status and unit cohesion (as assessed at Time 2) affected the significant mood outcomes observed. Also, we re-ran analyses to examine our secondary hypothesis utilizing the 3 -item job demands scale.

\section{Results}

The majority of participants in this study were enlisted soldiers (90\%), from infantry/gun crew-type occupational specialties $(77 \%)$, and from infantry, military police, or field artillery units (99\%). Table 1 presents the means, standard deviations, and categorical rates of the descriptive characteristics of the ARNG personnel groups at Time 1.

The mean time interval between the Time 1 and Time 2 assessments was 7.5 months [deployers $=7.3$ months (SD 0.34); non-deployers $=7.7$ months $(\mathrm{SD} \mathrm{1.5)}$ ]. Table 2 presents the means and standard deviations for each neuropsychological performance and mood outcome and work stress variables, by time and group. Job stress (quotient term) significantly increased over time [Time 1: 1.03 (SD 0.22); Time 2: 1.13 (SD 0.36); $\mathrm{F}(1,117)=10.9, \mathrm{P}=0.001$ ] as did job demands [Time 1: 30.9 (SD 5.2); Time 2: 32.4 (SD 5.3); $\mathrm{F}(1,117)=6.77$, $\mathrm{P}=0.01$ ], but job control did not [Time 1: 30.8 (SD 5.1); Time 2: 30.1 (SD 5.6); $\mathrm{F}(1,117)=2.04, \mathrm{P}=0.16]$. There
Table 1. Descriptive characteristics of study groups of Army National Guard (ARNG) soldiers at Time 1. (SD = standard deviation; WRAT3 = Wide Range Achievement Test, version 3; TOMM = Test of Memory Malingering; LOC = loss of consciousness; PCS = physical component summary; MCS = mental component summary; VR-12 = Veterans Rand 12-item Health Survey; PTSD = post-traumatic stress disorder)

\begin{tabular}{|c|c|c|c|c|}
\hline \multirow[t]{2}{*}{ Descriptives } & \multicolumn{2}{|c|}{$\begin{array}{l}\text { Deployed } \\
(\mathrm{N}=67)\end{array}$} & \multicolumn{2}{|c|}{$\begin{array}{l}\text { Non-deployed } \\
\quad(\mathrm{N}=52)\end{array}$} \\
\hline & Mean & SD & Mean & SD \\
\hline Age (years) & 28.4 & 8.3 & 25.7 & 7.2 \\
\hline Age $(\% \leq 35$ years $)$ & 79.1 & .. & 84.6 & .. \\
\hline Percentage of enlisted & 86.6 & .. & 96.2 & .. \\
\hline $\begin{array}{l}\text { Education (\% education } \\
\text { after high school) }\end{array}$ & 76.1 & .. & 57.7 & .. \\
\hline $\begin{array}{l}\text { Education ( } \% \text { of } 4 \text {-year } \\
\text { college or above) }\end{array}$ & 17.9 & .. & 13.5 & .. \\
\hline $\begin{array}{l}\text { WRAT3 - Reading } \\
\text { Standard Score }\end{array}$ & 102.9 & 9.7 & 102.2 & 7.7 \\
\hline TOMM score & 48.8 & 1.4 & 48.3 & 1.9 \\
\hline $\begin{array}{l}\text { Percentage of non-white, } \\
\text { Caucasian }\end{array}$ & 11.9 & .. & 20.0 & .. \\
\hline Percentage of married & 22.4 & .. & 29.4 & .. \\
\hline $\begin{array}{l}\text { Percentage of }>10 \text { years } \\
\text { ARNG service }\end{array}$ & 22.7 & .. & 16.3 & .. \\
\hline $\begin{array}{l}\text { Percentage of history of } \\
\text { prior head injury } \\
\text { with reported } \\
\text { LOC }>15 \text { minutes }\end{array}$ & 9.2 & .. & 3.8 & .. \\
\hline $\begin{array}{l}\text { Percentage of history of } \\
\text { prior overseas deployment }\end{array}$ & 19.7 & .. & 19.6 & .. \\
\hline $\begin{array}{l}\text { Familiarity with computers: } \\
\text { (\% very familiar versus } \\
\text { moderately, somewhat, } \\
\text { or not at all) }\end{array}$ & 29.9 & .. & 38.5 & .. \\
\hline $\begin{array}{l}\text { Physical functioning } \\
\text { (PCS from VR-12) }\end{array}$ & 54.2 & 5.1 & 52.5 & 6.0 \\
\hline $\begin{array}{l}\text { Mental functioning } \\
\text { (MCS from VR-12) }\end{array}$ & 54.5 & 7.5 & 52.1 & 9.2 \\
\hline $\begin{array}{l}\text { PTSD symptom severity, } \\
\text { summary score }\end{array}$ & 26.8 & 11.0 & 27.8 & 10.1 \\
\hline $\begin{array}{l}\text { Percentage of } \\
\text { presumptive PTSD }\end{array}$ & 6.1 & .. & 3.8 & .. \\
\hline Unit cohesion & 51.4 & 9.6 & 42.3 & 8.0 \\
\hline
\end{tabular}

were no significant differences over time between the deployed and non-deployed groups. The percentage of persons working in high job-strain jobs increased over time (Time 1: 19.5\%; Time 2: 29.7\%; McNemar's $X^{2}=4.0, \mathrm{P}=0.04$ ), with Time 2 rates higher in the nondeployed groups compared to the deployed group.

Among deployers, the most prevalent stressors reported, aside from separation from family or loved ones (28.4\%), were work-related factors: (i) lack of opportunities to further education (28.4\%), (ii) long-duty days $(24.2 \%)$, (iii) uncertain redeployment date (20.9\%), and (iv) boring or repetitive work (19.4\%). The most commonly reported peacekeeping-related experiences rated with moderate or extreme impact were: (i) seeing children victimized by war (34.3\%), (ii) seeing physical devastation (19.4\%), (iii) having contact with traumatized civilians (13.4\%), (iv) receiving hostile reactions from civilians they were 
Table 2. Neuropsychological performance and mood among deployed and non-deployed groups at Time 1 and Time 2. (SD = standard deviation; NES3 = Neurobehavioral Evaluation System, version 3; CPT = Continuous Performance Test; POMS = Profile of Mood States)

\begin{tabular}{|c|c|c|c|c|c|c|c|c|c|c|c|c|}
\hline \multirow[t]{4}{*}{ Outcomes } & \multicolumn{6}{|c|}{ Time 1} & \multicolumn{6}{|c|}{ Time 2} \\
\hline & \multirow{2}{*}{\multicolumn{2}{|c|}{$\begin{array}{l}\text { Deployed } \\
(\mathrm{N}=67)\end{array}$}} & \multicolumn{4}{|c|}{$\begin{array}{l}\text { Non-deployed } \\
(\mathrm{N}=52)\end{array}$} & \multirow{2}{*}{\multicolumn{2}{|c|}{$\begin{array}{l}\text { Deployed } \\
(\mathrm{N}=67)\end{array}$}} & \multicolumn{4}{|c|}{$\begin{array}{l}\text { Non-deployed } \\
(\mathrm{N}=52)\end{array}$} \\
\hline & & & \multicolumn{2}{|c|}{$\begin{array}{l}\text { Activated } \\
(\mathrm{N}=19)\end{array}$} & \multicolumn{2}{|c|}{$\begin{array}{l}\text { Non-activated } \\
(\mathrm{N}=33)\end{array}$} & & & \multicolumn{2}{|c|}{$\begin{array}{c}\text { Activated } \\
(\mathrm{N}=19)\end{array}$} & \multicolumn{2}{|c|}{$\begin{array}{l}\text { Non-activate } \\
\quad(\mathrm{N}=33)\end{array}$} \\
\hline & Mean & SD & Mean & SD & Mean & SD & Mean & SD & Mean & SD & Mean & SD \\
\hline \multicolumn{13}{|l|}{ Motor speed } \\
\hline $\begin{array}{l}\text { NES3 Finger Tapping: } \\
\text { Dominant, number of taps a } \\
\text { Non-dominant, number of taps }\end{array}$ & $\begin{array}{r}62.10 \\
54.50\end{array}$ & $\begin{array}{l}8.2 \\
7.8\end{array}$ & $\begin{array}{l}60.58 \\
54.32\end{array}$ & $\begin{array}{l}6.0 \\
4.5\end{array}$ & $\begin{array}{l}62.00 \\
53.67\end{array}$ & $\begin{array}{l}9.4 \\
7.2\end{array}$ & $\begin{array}{l}62.50 \\
55.90\end{array}$ & $\begin{array}{l}9.0 \\
8.6\end{array}$ & $\begin{array}{l}61.79 \\
57.00\end{array}$ & $\begin{array}{r}10.1 \\
8.0\end{array}$ & $\begin{array}{l}65.60 \\
59.00\end{array}$ & $\begin{array}{l}9.2 \\
8.8\end{array}$ \\
\hline \multicolumn{13}{|l|}{ Simple attention } \\
\hline $\begin{array}{l}\text { NES3 Sequences A: } \\
\text { time to complete (seconds) }\end{array}$ & 2.82 & 0.35 & 2.78 & 0.25 & 2.88 & 2.9 & 2.72 & 0.33 & 2.78 & 2.5 & 2.76 & 0.32 \\
\hline \multicolumn{13}{|l|}{ Executive function/working memory } \\
\hline $\begin{array}{l}\text { NES3 Sequences B: } \\
\text { number of errors }{ }^{\mathrm{b}} \\
\text { NES3 Sequences B: } \\
\text { time to complete (seconds) }{ }^{\mathrm{b}}\end{array}$ & 0.35 & 0.51 & 0.27 & 0.45 & 0.28 & 0.49 & 0.24 & 0.42 & 0.19 & 0.39 & 0.32 & 0.44 \\
\hline \multicolumn{13}{|l|}{ Visuo-scanning/processing speed } \\
\hline $\begin{array}{l}\text { NES3 Digit Symbol: } \\
\text { time to complete (seconds) }\end{array}$ & 4.55 & 0.15 & 4.54 & 0.15 & 4.57 & 0.12 & 4.54 & 0.15 & 4.52 & 0.15 & 4.53 & 0.13 \\
\hline \multicolumn{13}{|l|}{ Sustained attention } \\
\hline $\begin{array}{l}\text { NES3 CPT: response } \\
\text { time (milliseconds) }^{b} \\
\text { NES3 CPT: number of errors }{ }^{b}\end{array}$ & $\begin{array}{l}5.94 \\
0.40\end{array}$ & $\begin{array}{l}0.09 \\
0.57\end{array}$ & $\begin{array}{l}5.96 \\
0.62\end{array}$ & $\begin{array}{l}0.11 \\
0.62\end{array}$ & $\begin{array}{l}5.98 \\
0.53\end{array}$ & $\begin{array}{l}0.12 \\
0.67\end{array}$ & $\begin{array}{l}5.99 \\
0.40\end{array}$ & $\begin{array}{l}0.10 \\
0.55\end{array}$ & $\begin{array}{l}5.95 \\
0.20\end{array}$ & $\begin{array}{l}0.08 \\
0.36\end{array}$ & $\begin{array}{l}5.98 \\
0.45\end{array}$ & $\begin{array}{l}0.10 \\
0.73\end{array}$ \\
\hline \multicolumn{13}{|l|}{ Mood } \\
\hline $\begin{array}{l}\text { POMS tension } \\
\text { POMS depression } \\
\text { POMS anger } \\
\text { POMS confusion } \\
\text { POMS fatigue } \\
\text { POMS vigor a } \\
\text { POMS total score }\end{array}$ & $\begin{array}{r}9.04 \\
7.05 \\
9.16 \\
5.55 \\
5.18 \\
20.1 \\
115.84\end{array}$ & $\begin{array}{r}6.4 \\
9.1 \\
8.3 \\
4.6 \\
5.0 \\
5.7 \\
32.2\end{array}$ & $\begin{array}{r}9.39 \\
9.26 \\
10.26 \\
6.39 \\
5.86 \\
17.3 \\
123.85\end{array}$ & $\begin{array}{r}6.1 \\
9.2 \\
6.0 \\
3.2 \\
5.3 \\
4.8 \\
26.3\end{array}$ & $\begin{array}{r}8.13 \\
8.55 \\
9.39 \\
6.03 \\
6.79 \\
17.2 \\
121.95\end{array}$ & $\begin{array}{r}6.3 \\
9.7 \\
8.8 \\
4.8 \\
5.7 \\
6.2 \\
36.2\end{array}$ & $\begin{array}{r}8.01 \\
5.48 \\
9.42 \\
5.76 \\
6.39 \\
15.7 \\
119.46\end{array}$ & $\begin{array}{r}6.0 \\
7.7 \\
10.6 \\
4.5 \\
6.0 \\
7.2 \\
34.1\end{array}$ & $\begin{array}{r}10.32 \\
9.79 \\
11.53 \\
7.42 \\
7.21 \\
16.9 \\
129.71\end{array}$ & $\begin{array}{r}6.8 \\
11.2 \\
8.1 \\
3.9 \\
6.0 \\
4.5 \\
35.3\end{array}$ & \begin{tabular}{r|}
9.58 \\
11.78 \\
11.5 \\
6.45 \\
7.55 \\
15.8 \\
126.00
\end{tabular} & $\begin{array}{r}8.4 \\
11.9 \\
11.2 \\
5.1 \\
7.0 \\
7.5 \\
39.2\end{array}$ \\
\hline \multicolumn{13}{|l|}{ Work stress variables } \\
\hline $\begin{array}{l}\text { Job demands } \\
\text { Job control } \\
\text { Quotient score }\end{array}$ & $\begin{array}{l}32.28 \\
31.76\end{array}$ & $\begin{array}{l}5.2 \\
4.8\end{array}$ & $\begin{array}{l}30.42 \\
28.33\end{array}$ & $\begin{array}{l}3.4 \\
5.4\end{array}$ & $\begin{array}{l}28.41 \\
30.25\end{array}$ & $\begin{array}{l}5.2 \\
5.0\end{array}$ & $\begin{array}{l}33.36 \\
30.76\end{array}$ & $\begin{array}{l}5.1 \\
5.6\end{array}$ & $\begin{array}{l}31.05 \\
27.63\end{array}$ & $\begin{array}{l}6.3 \\
7.5\end{array}$ & $\begin{array}{l}31.15 \\
30.30\end{array}$ & $\begin{array}{l}4.5 \\
3.7\end{array}$ \\
\hline (demands/control) & 1.04 & 0.20 & 1.12 & 0.29 & 0.96 & 0.19 & 1.13 & 0.32 & 1.23 & 0.60 & 1.04 & 0.21 \\
\hline Percentage of high strain job & 22.4 & .. & 26.3 & .. & 9.1 &.. & 26.9 & .. & 36.8 & .. & 30.3 & .. \\
\hline
\end{tabular}

a Higher, more positive scores reflect better performance outcomes; otherwise, higher more positive scores reflect poorer outcomes.

${ }^{\mathrm{b}}$ Log-transformed; error scores have 1 added prior to transformation.

trying to help (13.4\%), (v) having to exercise self-restraint while patrolling (11.9\%), and (vi) patrolling or riding in areas where there were land mines $(9.0 \%)$.

\section{Influence of deployment: primary hypothesis}

We observed significant deployment effects indicating reduced proficiency on tasks involving motor skills and sustained attention (ie, number of taps made with the dominant and non-dominant hands on the Finger Tapping Test, log of the mean response time on the Continuous Performance Test, respectively) (table 3). The deployed group also demonstrated more proficient performance on a task involving working memory (log of the time to complete Sequences B) compared to the non-deployed, non-activated group. Deployment to Bosnia was not associated with changes in overall mood [total POMS score: $\mathrm{B}=-3.39,95 \%$ confidence interval (95\% CI) -7.28-0.504], however, when examining the distinct mood subscales, deployers reported significantly lower levels of vigor but also less depression symptomatology post-deployment, compared to non-activated, non-deployers. Moderate effect sizes ranged between $\mathrm{d}=0.28-0.45$ for the objective tasks and POMS depression and vigor.

\section{Influence of work stress: secondary hypothesis}

When we entered "working in a high-strain job in the period preceding Time 2 " into the models, the deployment 
Table 3. Examining the effects of deployment status on neuropsychological functioning and mood. ${ }^{\text {a }}(B=$ unstandardized parameter estimate for the deployed or activated group variables, which presents the absolute difference in adjusted mean outcome scores compared to the non-deployed, non-activated comparison group; $95 \% \mathrm{CI}=95 \%$ confidence interval; NES3 = Neurobehavioral Evaluation System, version 3; CPT = Continuous Performance Test; POMS = Profile of Mood States)

\begin{tabular}{|c|c|c|c|c|c|}
\hline Outcomes & Group & B & $95 \% \mathrm{Cl}$ & P-value b & Direction of effect \\
\hline \multicolumn{6}{|l|}{ Motor speed } \\
\hline \multicolumn{6}{|l|}{ NES3 Finger Tapping } \\
\hline Dominant hand, mean number of taps ${ }^{c}$ & $\begin{array}{l}\text { Deployed } \\
\text { Activated }\end{array}$ & $\begin{array}{l}-3.88 \\
-3.61\end{array}$ & $\begin{array}{l}-6.38--1.393 \\
-6.84--0.386\end{array}$ & $\begin{array}{l}0.002 \\
0.028\end{array}$ & Less proficient \\
\hline Non-dominant hand, mean number of taps ${ }^{c}$ & $\begin{array}{l}\text { Deployed } \\
\text { Activated }\end{array}$ & $\begin{array}{l}-3.84 \\
-2.67\end{array}$ & $\begin{array}{l}-5.55--2.14 \\
-4.53--0.82\end{array}$ & $\begin{array}{r}<0.001 \\
0.005\end{array}$ & $\begin{array}{l}\text { Less proficient } \\
\text { Less proficient }\end{array}$ \\
\hline \multicolumn{6}{|l|}{ Simple attention } \\
\hline \multirow[t]{2}{*}{ NES3 Sequences A: time to complete (seconds) d } & Deployed & -0.017 & $-0.059-0.025$ & 0.437 & .. \\
\hline & Activated & 0.061 & $-0.029-0.151$ & 0.186 & .. \\
\hline \multicolumn{6}{|l|}{ Executive function/working memory } \\
\hline \multirow[t]{2}{*}{ NES3 Sequences B: number of errors ${ }^{d}$} & Deployed & -0.045 & $-0.118-0.027$ & 0.222 & .. \\
\hline & Activated & -0.085 & $-0.262-0.091$ & 0.345 & .. \\
\hline \multirow[t]{2}{*}{ NES3 Sequences B: time to complete (seconds) d } & Deployed & -0.098 & $-0.136--0.060$ & $<0.001$ & More proficient \\
\hline & Activated & -0.039 & $-0.230-0.154$ & 0.694 & .. \\
\hline \multicolumn{6}{|l|}{ Visuo-scanning and processing speed } \\
\hline \multirow[t]{2}{*}{ NES3 Digit Symbol: time to complete (seconds) d } & Deployed & 0.018 & $-0.016-0.051$ & 0.300 & .. \\
\hline & Activated & 0.016 & $-0.033-0.066$ & 0.520 & .. \\
\hline \multicolumn{6}{|l|}{ Sustained Attention } \\
\hline \multirow[t]{2}{*}{ NES3 CPT: response time (milliseconds) ${ }^{d}$} & Deployed & 0.031 & $0.009-0.054$ & 0.006 & Less proficient \\
\hline & Activated & -0.028 & $-0.058-0.003$ & 0.078 &.. \\
\hline \multirow[t]{2}{*}{ NES3 CPT: total number of errors ${ }^{d}$} & Deployed & -0.038 & $-0.247-0.171$ & 0.721 & .. \\
\hline & Activated & -0.283 & $-0.496--0.071$ & 0.009 & .. \\
\hline \multicolumn{6}{|l|}{ Mood e } \\
\hline \multirow[t]{2}{*}{ POMS tension } & Deployed & -1.46 & $-2.83--0.09$ & 0.036 & .. \\
\hline & Activated & 0.184 & $-3.16-3.53$ & 0.914 & .. \\
\hline \multirow[t]{2}{*}{ POMS depression } & Deployed & -4.87 & $-7.93--1.80$ & 0.002 & Less depression \\
\hline & Activated & -2.12 & $-7.69-3.46$ & 0.457 &.. \\
\hline \multirow[t]{2}{*}{ POMS anger } & Deployed & -1.61 & $-3.49-0.261$ & 0.092 & .. \\
\hline & Activated & 0.351 & $-3.39-4.10$ & 0.854 & .. \\
\hline \multirow[t]{2}{*}{ POMS confusion } & Deployed & -0.595 & $-1.18--0.006$ & 0.048 & .. \\
\hline & Activated & 1.03 & $-1.15-3.22$ & 0.353 &.. \\
\hline \multirow[t]{2}{*}{ POMS fatigue } & Deployed & 0.449 & $-1.55-2.44$ & 0.659 &.$\cdot$ \\
\hline & Activated & 0.244 & $-2.70-3.19$ & 0.871 & .. \\
\hline \multirow[t]{2}{*}{ POMS vigor ${ }^{c}$} & Deployed & -2.70 & $-3.63--1.78$ & $<0.001$ & Decreased vigor \\
\hline & Activated & 1.35 & $-1.02-3.72$ & 0.265 &.. \\
\hline
\end{tabular}

a Model: Independent outcome variable = deployment status $(\mathrm{y} / \mathrm{n})$, activated status $(\mathrm{y} / \mathrm{n})$; covariates: age, education level (any post-high school education versus none), Time 1 measure of outcome. Deployed group $\mathrm{N}=67$; non-deployed, activated group $\mathrm{N}=19$; non-deployed, non-activated group $\mathrm{N}=33$.

${ }^{b}$ Bonferroni factor applied: bold = deployment or activated status associated with compromised performance or mood; italicized = deployment or activated status associated with better performance or mood.

${ }^{c}$ Higher, more positive B coefficients reflect better performance outcomes or more positive mood; otherwise, higher more positive B coefficients reflect poorer outcomes.

d Log-transformed

e For mood outcomes, Time 2 unit cohesion was included.

effects remained significant for the four domain-specific neuropsychological and two mood outcomes observed in the primary hypothesis testing described above. Working in a high-strain job was significantly and independently related to reduced performance with the non-dominant hand on the Finger Tapping task $(B=-3.67,95 \% \mathrm{CI}$ $-4.78--2.57, \mathrm{P}<0.001)$. There was no evidence of a significant interaction effect between deployment status and working in a high-strain job.
Influence of other factors on primary outcomes: sensitivity analyses

The pattern of deployment effects revealed with the core model following the primary hypothesis testing was not altered when we added, individually and post hoc, the following to the primary models: rank, history of head injury, hours of sleep, caffeine use, PTSD symptom severity, fatigue, or job engagement. There was no 
evidence of a significant interaction effect between deployment status and unit cohesion for either of the significant mood findings described above. Also, the observed results were not altered when we re-ran the analyses examining the secondary hypothesis utilizing job demands computed with 3-items.

\section{Discussion}

To our knowledge, this is the first study to examine neuropsychological functioning prospectively over a peacekeeping mission. It represents one of the few deployment health outcome studies to include pre-deployment examinations, objective measures of performance, a comparable non-deployed group, and timely post-deployment assessments. The findings indicate that deployment to Bosnia as part of a peacekeeping mission is associated with, at least in the short-term, shifts in objective cognitive and motor task performances specifically characterized by reduced proficiency in tasks of motor speed and sustained attention, and with reduced levels of vigor (primary hypothesis). Findings also associated with deployment include greater proficiency in a task involving working memory as well as reduced depression symptomatology. However, the deployment effects observed were not associated differentially with working in a high-strain job among the deployed group (secondary hypothesis).

\section{Interpretation}

Reduced proficiency of neuropsychological functioning associated with the Bosnia deployment (ie, fewer taps on the Finger Tapping Test and longer response times on the Continuous Performance Test) suggests a performance pattern shift characterized in part by a slowing in the rate of cognitive processing $(15,16,50)$. The findings cannot be attributed to pre-existing functional levels as we controlled for pre-deployment functioning. Also, the pattern of findings does not appear be related to other work- or lifestyle-related dimensions that we were able to examine. For example, the results were not impacted when we took into account aspects of occupational and traumatic stress, unit cohesion, job engagement, fatigue symptomatology, sleep, or recent caffeine use.

As anticipated, the Operation Joint Guard, SFOR10 deployment rotation involved minimal traumatic or life-threatening experiences. The types of potentially traumatic events and negative experiences (eg, uncertain redeployment date, long duty days, boring and repetitive work, and concerns about mines and unexploded ordinances) were similar and reported at comparable or lower prevalence rates to those in prior peacekeeping missions in Bosnia and Kosovo $(27,48,51)$.
Previous peacekeeping missions to the Sinai, Lebanon, and Croatia involving the monitoring of a ceasefire (similar to SFOR10 Bosnia) have been identified as environments where soldiers are prone to boredom as the nature of the work is characterized as tedious, with brief and rare moments of peak alertness $(2,3,52)$. In experimental studies, reduced vigilance as reflected by slowed response times on tasks involving sustained attention has been observed under conditions of prolonged work on the same repetitive task in simulated air traffic control tasks (53) and sentry work (54), but the cognitive model of boredom has not been fully characterized to date (55-57). Within the current study design, we were unable to directly examine whether the observed neuropsychological performance shift was related in a dose-effect manner to a specific experience or scenario involving repetitive work inherent in the deployment-theatre setting (such as sentry or routine patrol duties). However, endorsement of "boring or repetitive work" and "long duty days" were the more prevalent negative deployment job stressors described by the deployed group, post-deployment.

Findings suggest that, compared to non-activated deployment status, peacekeeping deployment is associated with more proficient performance in a task involving working memory (that is, response time on the Sequences B task). In the face of the above pattern of results, improved performance in this task, which requires more complex attention, may reflect the heightened arousal and effort needed for task completion $(50,58,59)$, skills which are required and emphasized during this type of deployment scenario. Regarding the finding of reduced depression symptomatology at Time 2 , there was little actual change in the mean level of depression symptomatology reported over time among the deployers, but by comparison, depression symptom levels increased from Time 1 to Time 2 among nondeployers (see table 2). Other prospective deployment studies have documented a homecoming effect, characterized by improved mood and other psychological symptoms when assessed most proximal to re-deployment (60). Although over $90 \%$ of the deployed group was assessed within 7-8 days of their return from Bosnia, no widespread evidence of a significant homecoming effect on mood and performance patterns was observed in this study.

Subjective reports of boredom suggest the deployed group may have encountered aspects of both an "underload" and traditional heightened job stress ("overload") situation, which in turn is reflected by the observed neuropsychological performance pattern and reduced vigor. Indeed, in sentry studies, tasks involving prolonged periods of repetitive, sustained attention with brief episodes requiring peak alertness are viewed as extremely frustrating and stressful (54). As discussed by 
Tucker et al (25), the expectation of clear differences in job strain trajectories over time among deployed groups may not always be present. In our study, although the absolute differences in quotient scores (Time 2 minus Time 1 value) did not differ between groups (table 2), job stress levels increased over time and within each group, with the highest prevalence of persons working high-strain jobs at Time 2 among the non-deployed groups. Although, in this study, the median level of job demands is higher and job control is lower than the median levels measured in the US Quality of Employment Survey (33), it is possible that the changing levels did not meet a threshold high enough to trigger effects on neuropsychological outcomes. However, it is important to note that while we did not find support for the hypothesis that working in a high strain job "explains" neuropsychological performances and mood associated with a peacekeeping deployment, working in a high strain job did independently influence performance and mood.

\section{Study strengths and limitations}

It is noteworthy to comment that the SFOR10 Bosnia deployment mission occurred in the immediate time period following the events of September 11, 2001. As such, the non-deployed group in this study experienced higher levels of operational tempo or pace than anticipated when the study was designed and initiated. In this regard, the non-deployed group (including both the activated and non-activated subsamples) was perhaps a better comparison group match to the deployed group in terms of operational tempo levels than might have been the case if the comparison group had been of the more traditional ARNG model with training only occurring one weekend per month. However, the a priori assumption that the deployed group would encounter significantly higher job strain over the deployment mission in contrast to the nondeployed groups was not observed. In addition, it is possible the 5-item job demands scale does not fully provide an assessment of military job demands and influenced the ability to examine the secondary hypothesis.

Nonetheless, the study includes a number of important methodological strengths enhancing our knowledge and ability to examine performance patterns related to a peacekeeping mission. Specifically, we successfully conducted the prospective assessment of a military cohort both before and after deployment, together with a comparable non-deployed group and the inclusion of objective performance measures along with subjective reports of psychological health.

\section{Generalizability}

The generalizability of the results to other military population groups comprised of active duty, female, or
non-US peacekeepers may be limited. The neuropsychological and mood pattern observed among Bosnia peacekeepers does contrast with that found in a recent prospective study of US Army soldiers deployed as part of Operation Iraqi Freedom (1), where deployment was associated with reduced proficiencies within functional domains involving sustained attention, learning, and memory, but better reaction time suggestive of a biologic response to traumatic stress. Together, the findings from these two studies provide evidence for the intuitive observation that deployment missions differ in terms of types or severity of stressors, which in turn may differentially impact post-deployment health, mood, and performance.

\section{Concluding remarks}

The results of this study provide evidence suggestive of changes in performance associated with a peacekeeping deployment, that is, the slowing of cognitive processing and reduced motor speed coupled with proficiency in a task involving more complex attention and working memory skills. But, the observed deployment effects are not associated with high job strain over deployment. What is not known at this point is whether deploymentrelated neuropsychological performance differences reflect transient or more permanent changes in functioning and mood and/or by extension occupational performance. The group differences observed do not appear to approach clinical thresholds indicative of neurological or psychological disease states (30). However, even small group shifts in the ability to maintain sustained attention and slowed motor speed may result in risk of performance problems in daily life. Awareness of potential differential patterns of neuropsychological functioning following deployment provides an opportunity to tailor training, protective, and preventive strategies to be more effective in mitigating performance risks.

\section{Acknowledgements}

Funding for this project was provided by the US Army Research and Materiel Command (DAMD17-00-10064) in a grant awarded to Boston University. We thank the soldier participants, their sponsoring military units, and the state-level Army National Guard Command for their time and support. The investigators have adhered to the policies for protection of human subjects as prescribed in Army Regulation 70-25, and the research was conducted in adherence with the provisions of $32 \mathrm{CFR}$ Part 219 (HSRRB Log No. A-9377.1; Boston University \#2001-164). Human subjects participated in the study after giving their free and informed voluntary consent. 
Job strain and deployment aspects of the study were presented in poster format at the 2003 and 2008 Work, Stress and Health Conferences in Toronto, Canada and Washington DC, USA, respectively. Please note that the opinions or assertions contained herein are the private views of the author(s) and are not to be construed as official or reflecting the views of the US government.

\section{References}

1. Vasterling JJ, Proctor SP, Amoroso PJ, Kane R, White RF. Neuropsychological outcomes of Army personnel following deployment to the Iraq War. JAMA. 2006;296:519-29.

2. Bartone PT, Adler AB, Vaitkus MA. Dimensions of psychological stress in peacekeeping operations. Mil Med. 1998;163:587-93.

3. Harris JJ, Segal DR. Observations from the Sinai: the boredom factor. Armed Forces Soc. 1985;11:235-48.

4. Hotopf M, Anthony D, Hull L, Ismail K, Unwin C, Wessely S. The health effects of peacekeeping (Bosnia, 1992-1996): a cross-sectional study-comparison with nondeployed military personnel. Mil Med. 2003;5:408-13.

5. Wessely S, Thomas S, Dandeker C, Greenberg N, Kelly V. Serving in Bosnia made me appreciate living in Bristol: stressful experiences, attitudes, and psychological needs of members of the United Kingdom Armed Forces. Mil Med. 2006; 171:376-80.

6. Thomas JL, Castro CA. Organizational behavior and the US peacekeeper [Chapter 8]. In: Britt TW, Adler AB, editors. The psychology of the peacekeeper: lessons from the field. Westport (CT): Praeger Press; 2003. p 127-46.

7. White RF, Proctor SP, Heeren T, Wolfe J, Krengel M, Vasterling JJ, et al. Neuropsychological function in Gulf War veterans: relationships to self-reported toxicant exposures. Am J Ind Med. 2001;40:42-54.

8. Proctor SP, White RF, Heeren T, Debes F, Gloerfelt-Tarp B, Appleyard M, et al. Neuropsychological functioning in Danish Gulf War veterans. J Psychopathol Behav Assess. 2003;25:85-94.

9. Vasterling JJ, Bremner JD. The impact of the 1991 Gulf War on the mind and brain. Philos Trans R Soc Lond B Biol Sci. 2006;361:593-604.

10. Adler AB, Litz B, Bartone PT. The nature of peacekeeping stressors [Chapter 9]. In: Britt TW, Adler AB, editors. The psychology of the peacekeeper: lessons from the field. Westport (CT): Praeger Press; 2003. p 149-68.

11. Thomas JL, Adler AB, Castro CA. Measuring operations tempo and relating it to military performance. Mil Psychol. 2005;17:137-156.

12. Iowa Persian Gulf Study Group. Self-reported illness and health status among Gulf War veterans: a population-based study. JAMA. 1997;277:238-45.

13. Steele L. Prevalence and patterns of Gulf War illness in Kansas veterans: association of symptoms with characteristics of person, place, and time of military service. Am J Epidemiol. 2000;152:992-1002.

14. Selye H. The stress of life. 2nd ed. New York (NY): McGrawHill; 1978. p 3-14, 145-170.

15. Hockey GRJ. Changes in operator efficiency as a function of environmental stress, fatigue, and circadian rhythms. In: Boff KR, Kaufman L, Thomas JP, editors. Handbook of perception and human performance. New York (NY): John Wiley \& Sons; 1986. p 1-49.

16. Hockey GRJ, Hamilton P. The cognitive patterning of stress states. In: Hockey GRJ, editor. Stress and fatigue in human performance. New York (NY): John Wiley \& Sons; 1983. p 331-62.

17. Karasek RA. Job demands, job decision latitude, and mental strain: implications for job redesign. Adm Sci Q. 1979;24:285-311.

18. Karasek R, Brisson C, Kawakami N, Houtman I, Bongers P, Amick B. The Job Content Questionnaire (JCQ): an instrument for internationally comparative assessments of psychosocial job characteristics. J Occup Health Psychol. 1998;3:322-55.

19. Proctor SP, White RF, Robins TG, Echeverria D, Rocskay AZ. The effect of overtime work on cognitive function in automotive workers. Scand J Work Environ Health. 1996;22(2):124-32.

20. Britt TW, Adler AB. Stress and health during medical humanitarian assistance missions. Mil Med. 1999;164:275-79.

21. Griffith J, Vaitkus M. Relating cohesion to stress, strain, disintegration, and performance: an organizing framework. Mil Psychol. 1999;11:27-55.

22. Bleise PD, Castro CA. Role clarity, work overload, and organizational support: multilevel evidence of the importance of support. Work Stress. 2000;14:65-73.

23. Bleise PD, Castro CA. The Soldier Adaption Model (SAM): applications to peacekeeping research [Chapter 11]. In: Britt TW, Adler AB, editors. The psychology of the peacekeeper: lessons from the field. Westport (CT): Praeger Press; 2003. p 185-204.

24. Ippolito J, Adler AB, Thomas JL, Litz BT, Holzl R. Extending and applying the demand-control model: the role of soldier's coping on a peacekeeping deployment. J Occup Health Psychol. 2005;10:452-64.

25. Tucker JS, Sinclair RR, Mohr CD, Adler AB, Thomas JL, Salvi AD. A temporal investigation of the direct, interactive, and reverse relations between demand and control and affective strain. Work Stress. 2008;22:81-95.

26. Campbell SJ, Ritzer DR, Valentine JN, Gifford RK. Operation Joint Guard (SFOR) Bosnia: assessment of operational stress and adaptive coping mechanism of soldiers. Washington (DC): Walter Reed Army Institute of Research; 1998. p 1-67. Technical report, number 19990318045.

27. Ritzer DR, Campbell SJ, Valentine JN. Human dimensions research during Operation 'Joint Guard,' Bosnia. US Army Med Dep J. 1999;8:5-16.

28. Cohen J. Statistical power analysis for the behavioral sciences. 2nd ed. Hilsdale (NJ): Lawrence Earlbaum Associates; 1988. p 25-7.

29. Proctor SP, Letz R, White RF. Validity of a computer-assisted 
neurobehavioral test battery in toxicant encephalopathy. NeuroToxicol. 2000;21:703-14.

30. White RF, James KE, Vasterling JJ, Letz R, Marans K, Delaney R, et al. Neuropsychological screening for cognitive impairment using computer-assisted tasks. Assessment. 2003;10:86-101.

31. Morgan WP, O'Connor PJ, Sparling PB, Pate RR. Psychological consideration of the elite female distance runner. Intl J Sports Med. 1987;8 suppl:124-31.

32. Karasek RA. Job Content Questionnaire and user's guide. Lowell (MA): University of Massachusetts; 1985. p 16-9.

33. Landsbergis PA, Schnall PL, Warren K, Pickering TG, Schwartz JE. Association between ambulatory blood pressure and alternative formulations of job strain. Scand J Work Environ Health. 1994;20:349-63.

34. Schnall PL, Landsbergis PA, Baker D. Job strain and cardiovascular disease. Ann Rev Pub Health. 1994;15:381411.

35. Bosma H, Peter R, Siegrist J, Marmot M. Two alternative job stress models and the risk of coronary heart disease. Am J Public Health. 1998;88:68-74.

36. O'Bryant S, Engel L, Kleiner J, Vasterling JJ, Black F. Test of memory malingering (TOMM) trial 1 as a screening measure for insufficient effort. Clin Neuropsychologist. 2007;21:511-21.

37. Kazis LE, Wilson N, Skinner K, Lee A, Rogers W, Ren XS, et al. Health status and outcomes of veterans: Physical and Mental Component Summary Scores Veterans SF-12 1998 National Survey of Hospitalized Patients [executive report]. Bedford (MA): Center for Health Quality, Outcomes \& Economic Research; 1999. p 140-51.

38. Weathers FW, Litz BT, Herman DS, Huska JA, Keane TM. The Post-traumatic Stress Disorder (PTSD) Checklist: reliability, validity, and diagnostic utility. In: Annual Meeting of International Society for Traumatic Stress Studies; San Antonio (TX), October, 1993. San Antonio (TX): International Society for Traumatic Stress Studies; 1993.

39. Ruggiero KJ, Del Ben K, Scotti JR, Rabalais AE. Psychometric properties of the Post-traumatic Stress Disorder Checklistcivilian version. J Traum Stress. 2003;16:495-502.

40. Hoge CW, Castro CA, Messer SC, McGurk D, Cotting DI, Koffman RL. Combat duty in Iraq and Afghanistan, mental health problems, and barriers to care. New Engl J Med. 2004;351:13-22.

41. Beurskens AJ, Bultmann U, Kant I, Vercoulen JH, Bleijenberg G, Swaen GM. Fatigue among working people: validity of a questionnaire measure. Occup Environ Med. 2000;57:353-57.

42. Bultmann U, Kant I, Kasl SV, Beurskens AJ, van den Brandt PA. Fatigue and psychological distress in the working population: psychometrics, prevalence, and correlates. J Psychosom Res. 2002;52:445-52.

43. de Vries M, Soetekouw PM, van der Meer JW, Bleijenberg G. Fatigue in Cambodia veterans. Q J Med. 2000;93:283-89.

44. Marlow DH, editor. New manning system field evaluation. Washington (DC): Walter Reed Army Institute of Research; 1987. Technical report, number 5.
45. Britt TW, Castro CA, Adler AB. Self-engagement, stressors, and health: a longitudinal study. Pers Soc Psychol Bull. $2005 ; 31: 1475-86$.

46. Adler AB, Dolan CA, Castro CA. US Soldier peacekeeping experiences and wellbeing after returning from deployment to Kosovo. In: 36th International Applied Military Psychology Symposium, 11-15 September 2000; IAMPS 2000 proceedings: changing Mission for the 21st Century. Split (Croatia): Ministry of Defence Zagreb; 2001. p 30-4.

47. Litz BT, King LA, King DW, Orsillo SM, Friedman MJ. Warriors as peacekeepers: features of the Somalia experience and PTSD. J Consult Clin Psychol 1997;65:1001-10.

48. Maguen S, Litz BT, Wang JL, Cook M. The stressors and demands of peacekeeping in Kosovo: Predictors of mental health response. Mil Med. 2004;169:198-206.

49. Cronbach LJ, Furby L. How we should measure 'change': or should we? Psychol Bull. 1970;74:68-80.

50. Lezak MD, Howieson DB, Loring DW, editors. Neuropsychological Assessment. 4th ed. New York (NY): Oxford University Press; 2004. p 349-51.

51. Castro CA, Bienvenu RV, Huffman AH, Adler AB. Soldier dimensions and operational readiness in U.S. Army Forces deployed to Kosovo. Rev Int Serv Sante Forces Armees. 2000;73:191-200.

52. Carlstrom A, Lundin T, Otto U. Mental adjustment of Swedish UN soldiers in South Lebanon in 1988. Stress Med. 1990;6:305-10.

53. Thackray RI, Bailey JP, Touchstone RM. Physiological, subjective and performance correlates of reported boredom and monotony while performing simulated radar control task. In: Mackie RR, editor. Vigilance: theory, operational performance and physiological correlates. New York (NY): Plenum Press; 1977. p 203-15.

54. Johnson RF, McMenemy DJ. Target detection, rifle marksmanship, and mood during three hours of simulated sentry duty. Proc Human Factors Soc. 1989;33:1414-8.

55. Hill AB, Perkins RE. Towards a model of boredom. Br J Psychol. 1985;76:235-40.

56. Perkins RE, Hill AB. Cognitive and affective aspects of boredom. Br J Psychol. 1985;76:221-34.

57. Pattyn N, Neyt X, Henderickx D, Soetens E. Psychophysiological investigation of vigilance decrement: boredom or cognitive failure? Physiol Behav. 2008;93:369-78.

58. Strauss E, Sherman EMS, Spreen O, editors. A compendium of neuropsychological tests-administration, norms, and commentary. 3rd ed. New York (NY): Oxford University Press; 2006. p 546.

59. White RF, Gerr F, Cohen RF, Green R, Lezak MD, Lybarger J, et al. Criteria for progressive modification of neurobehavioral batteries. Neurotoxicol Teratol. 1994;16:511-24.

60. Bleise PD, Wright KM, Adler AB, Thomas JL, Hoge CW. Timing of postcombat mental health assessments. Psychol Sci. 2007;4:141-8.

Received for publication: 29 December 2008 